Stoa

Vol. 2, No. 3, 2011, pp. 49-73

ISSN en trámite.

\title{
LA CIUDAD SUSTENTABLE COMO ENTORNO CLAVE DE LA TECNOSFERA DE LA SOCIEDAD DEL CONOCIMIENTO
}

\author{
José ANTONiO HeRnAnZ MORAL \\ Facultad de Filosofía. \\ Universidad Veracruzana \\ jhernanz@uv.mx \\ FERNANDO NOEL WINFIELd REYES \\ Facultad de Arquitectura \\ Universidad Veracruzana \\ carpediem33mx@yahoo.com.mx
}

RESUMEN: El espacio antropológico típico de la sociedad del conocimiento es el urbano tanto por ser el que acumula la mayor parte de la población humana como por ser el más propicio para una economía y una política basadas en el conocimiento. Precisamente por ello, uno de los retos más relevantes para el urbanismo contemporáneo es el diseño y realización de ciudades sustentables. Ahora bien, la idea de una ciudad sustentable es solidaria con un cierto tipo de concepción de la relación cultural entre biosfera (naturaleza), noosfera (pensamiento) y tecnosfera (acción humana); por todo ello, en este artículo se explora la caracterización de la idea de sustentabilidad dentro de la perspectiva más amplia de la tecnosfera de la sociedad del conocimiento.

PALABRAS CLAVE: sociedad del conocimiento; urbanismo y sustentabilidad; desarrollo sustentable; tecnosfera.

SUMMARY: The typical anthropological space in the society of knowledge is the city, becouse it is the one that accumulates most of the human population and becouse it is the most suitable for economy and politics knowledge-based. Precisely for this reason, one of the most significant challenges for the contemporary urbanism is the design of sustainable cities. However, the idea of a sustainable city is coherent to a certain kind of conception of the cultural relationship between the biosphere (nature), noosphere (thought) and technosphere (human action). So, this paper explores the characterization of the idea of sustainability within the broader perspective of the technosphere of the society of knowledge. 
KEY WORDS: Society of knowledge; urbanism and sustainability; sustainable development; technosphere.

\section{En la ciudad de la información y el conocimiento.}

La crisis de la ciudad contemporánea es una problemática que ha sido objeto de estudio desde los orígenes del urbanismo moderno (Winfield, 2004). Esta problemática ha sido explorada desde distintos enfoques y disciplinas (Parker, 2004; González Romero y Pérez Bourzac, 2004) en un contexto de creciente complejidad y globalización, allí donde se reconoce que el modo de desarrollo económico prevaleciente no es necesariamente el más sustentable (Winfield, 2005). Ahora bien, la Red habrá de jugar un papel tan crucial en la urbanidad del siglo XXI como en su momento el ágora lo fue para la polis griega y en los esquemas de planificación urbana que se derivaron entonces; el impacto de las nuevas tecnologías de la información sobre lo urbano puede ser analizado a partir de tres ámbitos más o menos amplios (Parker 2004, p. 164)

Una de las funciones esenciales de la ciudad es reunir individuos, generar interacciones e intercambios, sean estos de índole social, económica o cultural. Tradicionalmente los asentamientos humanos y ciudades se han caracterizado por ser la sede donde se concentran los poderes económico, político y religioso. No es extraño encontrar entonces que las innovaciones científicas y tecnológicas asociadas con el uso de las redes comenzaron por conectar los centros financieros más grandes a través de rutas de navegación o mediante líneas de comunicación como el telégrafo, por ejemplo entre Londres, París y Nueva York. A partir de la Revolución Industrial el desarrollo del ferrocarril y de la navegación fluvial y marítima posibilitaron nuevos ejes de comunicación entre ciudades, generando impactos sobre el modo y la estructura de ocupación de las actividades en el territorio. A lo largo de las vías o los cruces y nodos se fueron conformando nuevos asentamientos y núcleos de población con vocaciones específicas, por ejemplo, College Station en Texas (primer campus de la Universidad Tecnológica de Texas A\&M).

En los últimos años, la columna vertebral de la Internet ha sido construida sobre principios similares, aunque con una súper-concentración de infraestructura y tráfico entre los principales centros financieros de los Estados Unidos (Nueva York-Los Ángeles), de tal suerte que el ciber-mapa refleja, con 


\begin{tabular}{|l|l|}
\hline \multirow{2}{*}{$\begin{array}{l}\text { IMPACTOS DE LOS } \\
\text { PROCESOS } \\
\text { VINCULADOS AL } \\
\text { CAMPO DE }\end{array}$} & a) en las ciudades reales o existentes. \\
\cline { 2 - 2 } $\begin{array}{l}\text { CIENCIA, } \\
\text { TECNOLOGíA, } \\
\text { SOCIEDAD E } \\
\text { INNOVACIÓN } \\
\text { (CTS+i) }\end{array}$ & $\begin{array}{l}\text { b) en diseño de la ciudad y la planeación } \\
\text { (CADitorial: diseño asistido por computadora } \\
\text { y los sistemas geográficos de información } \\
\text { (GIS: geographic information systems). }\end{array}$ \\
\cline { 2 - 2 } & $\begin{array}{l}\text { c) en el mundo urbano real y su interacción } \\
\text { con el ciberespacio o mundo virtual } \\
\text { (es decir, el modo en el que percibimos, } \\
\text { experimentamos, diseñamos y "construimos" } \\
\text { en el sentido más amplio posible nuestra } \\
\text { "nueva" realidad urbana). }\end{array}$ \\
\hline
\end{tabular}

algunas variaciones, la supremacía comercial y, en particular, el modo de expansión territorial ligado al modo empresarial norteamericano de crecimiento De este modo, a través de los sistemas de visualización y mapas es posible representar gráficamente las redes de flujos y su intensidad en el territorio, considerando las interacciones entre varias ciudades.

Ahora bien, aunque este proceso es urbanístico, no se queda en la pura traza urbana, sino que expresa una transformación del topos en el que se configuran las sociedades contemporáneas. Desde la década de los años 1990 y posteriormente, Castells (2000) y otros autores han estudiado las relación entre acceso a la Internet y modos de vida urbanos. Contrario a lo que han planteado distintas utopías y visiones urbanas modernas como La Ciudad Contemporánea de Le Corbusier o Broadacre City de Frank Lloyd Wright, no sólo la expansión, sino sobre todo la alta concentración urbana es característica de la revolución informática y la acumulación del capital en ciudades que compiten entre sí. 
La disponibilidad de centros o áreas de conocimiento especializado se ha convertido en un factor clave para la localización de empresas y negocios. Pero no basta la especialización: esta debe ir aparejada de una adecuada conectividad a redes físicas y virtuales en el mundo contemporáneo crecientemente globalizador. Silicon Valley en California ha sido uno de los casos más estudiados en el urbanismo reciente, en el que el sistema industrial se organiza sobre el territorio a partir de redes regionales. Las compañías instaladas en la región han basado su desarrollo en crear nuevos mercados, productos y aplicaciones desde el conocimiento.

A esto se ha denominado economías de aglomeración o concentración. Firmas especializadas compiten intensamente al tiempo que ajustan su producción con las fluctuaciones del mercado y la innovación tecnológica. Es a partir de estas experiencias que se ha pensado que las redes sociales y los mercados de empleo abierto generan capacidades de experimentación y espíritu emprendedor. Con lo que los límites entre empresas, centros de negocios, instituciones locales, asociaciones y universidades se flexibilizan, generando condiciones atractivas para el establecimiento de profesionales de las tecnologías de la información que buscan un acceso rápido y confiable a las infraestructuras de vanguardia. Sin embargo, en la realidad, este modo de construir la ciudad todavía tiene que demostrar no sólo su viabilidad social y financiera, sino sobre todo ecológica. Es aquí donde entroncamos con el discurso de la sustentabilidad.

Es evidente que las nuevas tecnologías de la información han tenido un impacto significativo en la geografía humana, pero eso no quiere decir que las nuevas lógicas del capital y su expansión o densificación en la ciudad y el territorio son las únicas posibles.

La visión unitaria de la ciudad del futuro, la ciudad e-futuro o e-topía como la ha llamado Mitchell (2000), un mundo o entorno de intensa actividad durante las 24 horas del día, con viviendas que son también el espacio para el trabajo a partir de la interconexión, donde los encuentros se organizan conforme a lugares y tiempos electrónicamente gestionados, una ciudad flexible y descentralizada que integra espacios virtuales al igual que físicos. Una ciudad que puede estar más cerca de la utopía que de la realidad en el contexto de asimetrías globales entre pobreza y riqueza, en la integración/desintegración de lo 
local a lo global. Ese es el escenario en que primordialmente se está dirimiendo el diseño del espacio antropológico de las sociedades del conocimiento.

\section{El desarrollo como reto de fin de la modernidad. ${ }^{1}$}

Lo que parece quedar claro es que toda esa configuración de este espacio antropológico en que nos está tocando en suerte construir el actual mundo humano, aunque no sea teleológica, responde a toda una dinámica social, cultural, civilizatoria. El tipo de economía y política propios de una sociedad del conocimiento se rige por la máxima interconexión en el mínimo espacio y con la mayor velocidad entre los agentes del conocimiento (la configuración red entre individuos se superpone a la red de flujos de la estructura urbana), lo que hace que confluya el espacio físico de la ciudad con el espacio virtual de la interacción de/por el conocimiento. Todo ello, empero, sólo es posible en un esquema más amplio, el que hace de proyecto global la idea de desarrollo, y de cierto tipo.

Nuestra idea actual de desarrollo suele estar ligada al concepto "desarrollo sostenible", que remite, al menos, al menos, a los siguientes elementos: (i) prioridad del desarrollo económico; (ii) búsqueda de modelos comprometidos con el desarrollo social; (iii) promoción de la capacidad para resolver las necesidades de las sociedad actuales; (iv) asunción del reto de hacerlo sin hacer peligrar la capacidad de las próximas generaciones de resolver sus problemas (es decir, se compromete a no agotar los recursos disponibles, a resolver los problemas ambientales heredados y a generar el menor número posible de problemas ambientales futuros; (v) aceptación como una de sus prioridades la distribución social real de la riqueza, o lo que es lo mismo, el imperativo de erradicar la pobreza estructural; (vi) sus estrategias básicas son el desarrollo tecnológico, el fortalecimiento de una organización social responsable (democrática, con una sociedad civil activa y comprometida) y el impulso de una cultura de la gestión ambiental.

En este contexto, parece clara la relación entre "desarrollo" y "desarrollo tecnológico", toda vez que uno de los elementos que mejor nos permiten hablar de nuestro presente es su caracterización como sistema científicotecnólogico; sin embargo, quedarse tan sólo en esa relación es tan ingenuo co-

${ }^{1}$ Para revisar este punto con más detenimiento, cfr. Hernanz 2004. 
mo peligroso, ya que es preciso modular esa convicción desde otros elementos articuladores de nuestro presente (Lomborg 2003, pp. 458-472), especialmente la correlación con el mundo natural, con el ambiente. El problema crucial de todo este planteamiento es que parece surgir una dicotomía irreconciliable entre el desarrollo de la polis y el de la naturaleza al plantear cómo consolidar el desarrollo humano; de un lado, la tecnociencia y la economía del conocimiento impulsan la ciudad-región como espacio antropológico (para nosotros, entorno clave de nuestra tecnosfera), por otro, la conciencia ecológica retrae el fortalecimiento de la red urbana en aras de una más viable armonización con la naturaleza (como concepto-expresión de nuestra biosfera), que parece exigir cualquier propuesta de sustentabilidad. Es, como puede suponerse, esta tensión biosfera-tecnosfera lo que debemos discutir para plantear cualquier propuesta de ciudad sustentable para la tecnosfera de la sociedad del conocimiento.

Ahora bien, pudiera parecer que la idea del "ambiente" o "naturaleza" (para los efectos del presente artículo se usarán indistintamente) desde la que problematizamos y damos respuesta a los problemas del desarrollo corresponde a la "realidad física", que está bien determinada y que responde a una caracterización homogénea por parte de los seres humanos que habitamos nuestro planeta actualmente. Sin embargo, como se discute a continuación, esta idea es más bien falsa, por lo que cualquier planteamiento sobre nuestro problema exige una revisión de la relación entre el hombre con su medio, tanto directamente como a través de la mediación de la técnica. Si se consigue esto, podremos reformular la relación entre tecnología y cultura de tal manera que se rompe con la fórmula de una desarrollo lineal y lleno de paradojas a la hora de vincularlo con la diversidad cultural y las necesidades sociales contemporáneas.

\section{La inserción de la naturaleza en la cultura. ${ }^{2}$}

Seguramente, uno de los problemas más interesantes para los seres humanos, es el problema de su propia definición. Es bastante común que nos entendamos a nosotros mismos a partir de la contraposición de las cosas que se

${ }^{2}$ Una primera versión de las ideas de este epígrafe fue expuesta de manera más breve y provisional en Hernanz (2006). 
dan a nuestro alrededor; por lo que nos dice la psicología evolutiva, uno de los mayores logros del bebé, a los pocos meses de haber nacido, es darse cuenta de que la realidad no es una prolongación natural de su propia mano, sino que es "algo distinto", "totalmente diferente".

Esa experiencia, por la que todos hemos tenido que pasar, configura uno de los principales mecanismos de clasificación de la realidad para el ser humano: lo "mío", que está dentro de mí (de alguna manera), y lo "no mío", que es externo a mí, y con lo que interactúo. En esta relación bipolar elemental parece excluirse otra cosa que no es "mía", pero que se comporta "como yo", el resto de los seres humanos. Aunque pueda parecer muy elemental, este mecanismo de inclusión-exclusión funciona, y no sólo en tanto que individuos, sino en tanto que especie, con el resultado de que, con mayor o menor grado de comunión con la naturaleza, el ser humano en todas las culturas se ve como una singularidad en la realidad, y una singularidad que se integra de alguna manera en el todo de su cosmovisión. Precisamente ese "de algún modo" es lo que configura la relación simbólica hombre-naturaleza (Zubiri 1980, pp. 114-120).

En efecto, el ser humano, que de manera constante se pregunta por sí y por la relación con las demás cosas, articula la realidad en torno a lo que se viene llamando cultura. Bajo el término "cultura" se conjunta modos de vida, costumbres, arte, tecnología, relaciones políticas, etc., de los diversos grupos humanos, y en diversos momentos de la historia; ahora bien, en muchas ocasiones, al entenderse que la cultura tiene que ver con el "espíritu", y por lo tanto con el ámbito en que cada quién adquiere conciencia de sí, y da sentido a la realidad, parece dejar a un lado la naturaleza, determinándola nada más como ese sustrato material en que se desarrolla. Es más, la reflexión sobre la cultura -eurocéntrica en sus raíces- de buena parte del siglo XX se cebó en la idea de que sólo las culturas más primitivas conceden a la naturaleza un valor preponderante en el discurso antropológico, mientras que las más desarrolladas o evolucionadas ven en ella tan sólo ese sustrato. Del mismo modo, a medida que una cultura va madurando y se va haciendo más compleja, parece querer abandonar paulatinamente su dependencia de la naturaleza, esto es, del orden de lo "físico". 
Nos encontramos, por lo tanto, con una de las más importantes escisiones de la realidad en la mayor parte de las concepciones antropológicas: la separación entre hombre y naturaleza. Hoy, a principios del siglo XXI, esta separación se presenta de forma muy diversa, desde ser un pequeño matiz (culturas indígenas de la mayor parte del mundo) a presentarse como una auténtica escisión (culturas urbanas, preferentemente en las sociedades postindustrializadas); el problema que trae consigo esta amplia gama de interpretaciones de la naturaleza en la cultura no tiene que ver fundamentalmente con el respeto a los usos que de ella se pueda hacer por unos u otros (que no es, por otra parte, un problema de escasa importancia), sino más bien con las probabilidades de supervivencia de las culturas en su conjunto (es decir, de la especie humana), si se continúa con el actual sistema global de gestión del ambiente (Wallerstein 2001, pp. 88-99).

En definitiva, de manera general podemos afirmar que el ser humano se sabe unido a la naturaleza, mas al mismo tiempo poseedor de algún rasgo cualitativo que le distingue de ella; esa relación paradójica se expresa en la cultura de múltiples maneras, como pueden ser las manifestaciones artísticas (naturaleza como expresión de los estados de ánimo), religiosas (la vuelta a la simplicidad natural taoísta, el acceso a los divino a través de la unión mística con la naturaleza) o científicas (todos los procesos de explicación del universo a partir de conjuntos de leyes). Sin comprender esa tensión cultural es imposible plantear escenarios realistas de desarrollo, pues la voluntad de sobrevivir de nuestra especie, en nuestro momento histórico, no parece ser suficiente si va ligada tan sólo al desarrollo científico-tecnológico; para que el sistema tecnocientífico sea realmente una herramienta de desarrollo humano, debe insertarse en el universo simbólico de las diversas culturas (en la medida en que éstas lo demanden), y hacerlo de forma propositiva e integradora de lo humano en el orden natural.

\section{La relación hombre-naturaleza en la cosmovisión occidental.}

En toda cultura se da una idea general de la realidad, una composición de lugar que permite ordenar simbólicamente todo cuanto acontece y da sentido, en definitiva, a cuanto pasa, al tiempo que dinamiza los proyectos personales y colectivos en la certeza de que lo real tiene una solución de continuidad cohe- 
rente con ese "universo simbólico". A todo ello lo denominamos cosmovisión, y en buena medida podemos comprender los avatares de cualquier cultura si somos capaces de entender la lógica interna de su cosmovisión. Por lo tanto, para intentar dar respuesta a los retos del desarrollo no hemos de fijarnos sólo en nuestro horizonte temporal, por el que somos "hombres del siglo XXI", sino que debemos hacerlo también en el horizonte de nuestra cosmovisión, por el que somos "hombres del siglo XXI, con una cosmovisión occidental"; estos dos parámetros -el histórico y el de la idea de mundo- son los que nos permiten ubicarnos en el modo de afrontar cualquier problema cultural, y el caso del desarrollo no es una excepción; desde los hallazgos que hagamos desde nuestro tiempo y nuestra cultura, podremos hacer propuestas sobre ella y que sean factibles, coherentes con nuestra mentalidad y compartibles con otras culturas.

Dicho esto, pasemos a revisar, al menos en sus características básicas, cómo se ha venido dando la relación hombre-naturaleza en la cosmovisión occidental, para así ver de qué manera estamos incluyendo la naturaleza en nuestro actual universo simbólico. Para ello vamos a fijarnos en el devenir de uno de sus productos culturales más característicos: la filosofía. El discurso filosófico occidental, como en el resto de las culturas, pretende ser una búsqueda genuina de la sabiduría, entendida ésta como un saber práctico que permita, a quien hace buen uso de él, saber vivir. En este sentido, la filosofía occidental busca arrojar luz sobre la paradoja misma en qué consiste la existencia humana en su relación con el mundo. El modo en que lo resuelve, en general, es con la exaltación de lo humano respecto al resto de la realidad, y muy especialmente respecto a la naturaleza.

El motivo de todo ello es muy simple, a pesar de que sigue planteando, hasta la fecha, problemas irresolubles. Como en todas las demás culturas, la occidental parte de la convicción de que lo real constituye una unidad (por ese motivo es legítimo fiarse de la propia cosmovisión), y es unidad intrínseca (es decir, resultante de las propias características de la realidad) (Wallerstein 2001, pp. 197-199). Quien conozca el principio por el que se da esa unidad intrínseca, es sabio, y podrá vivir sabiamente; ciertamente pueden ser diversas las formas en las que es viable el conocimiento de esa unidad, pero la única que parece universalizable es la racionalidad, de ahí el valor que Occidente 
ha dado a la ciencia, y que la filosofía occidental sea, más que ninguna otra cosa, racional, en el sentido de que busca el principio explicativo, más que el principio generativo, de lo real.

Ahora bien, a pesar de que los primeros filósofos afirmaron que ese principio explicativo era un elemento natural (agua, aire, fuego, lo indeterminado, etc.) podemos afirmar que Occidente encuentra la clave de su comprensión del mundo a partir de dos autores: Pitágoras y Protágoras. El primero da un salto teórico espectacular en la propia tradición occidental al afirmar que el principio de lo real son los números (y, por lo tanto, unos conceptos racionales), mientras que el segundo acuña para nuestra cultura la lapidaria frase "el hombre es la medida de todas las cosas". A partir de la interpretación que se hace de ambos, fundamentalmente del segundo, se consolida en la mentalidad occidental la idea de que la naturaleza es un bien que está al servicio del hombre, y que puede ser explotado adecuadamente para hacer que el ser humano tenga una vida más plena y digna. Como puede verse, no sólo hay una escisión dicotómica entre hombre y naturaleza, sino que además es una escisión que pone uno de los elementos subordinado al otro; la interacción entre hombre y naturaleza, así entendida, genera una lógica muy peculiar de la relación: el ser humano se desarrolla -es decir, hace físicas las potencialidades de su pensamiento- a expensas de la explotación de su ambiente.

En los siglos siguientes, diversos han sido los factores que han servido para apuntalar esta escisión, aunque entre ellos debemos tener en cuenta el derecho romano, que cimenta nuestra moderna concepción del derecho a la propiedad, y el cristianismo, que asume literalmente el mandato "creced, multiplicaos, llenad la tierra y sometedla". Estas ideas, lentamente acrisoladas en la mentalidad occidental, ayudan a entender el éxito de la distinción sujetoobjeto que, desde el comienzo de la Modernidad hasta bien entrado el siglo $\mathrm{XX}$, han servido para ratificar la separación entre el hombre y la naturaleza. Dos son, en ese sentido, los modelos que principalmente han calado en nuestra imagen del mundo en las primeras centurias de la Modernidad (del siglo XV al XIX): la de la relación con la naturaleza a partir de la correlación sujeto-objeto y la de la relación con la naturaleza a partir de la correlación macrocosmos-microcosmos; y a pesar de las distinciones que se dan entre los dos, ambos se basan en la idea de que el hombre es el centro de la realidad, 
tanto por ser la medida de todas cosas como por estar en la cúspide del proceso creativo de Dios.

Ahora bien, esos dos sentidos entran en crisis a lo largo del siglo XIX, y están muy fuertemente cuestionados en el siglo XX (Quintanilla 1995, pp. 204-206). Sin embargo, en este periodo de tiempo pervive la idea de que el hombre está separado de la naturaleza y que la puede controlar a su libre disposición (con el auxilio de la ciencia y la tecnología). De este modo, en la cosmovisión occidental de nuestro presente la naturaleza aparece como el "escenario" en que se da lo humano, es algo objetivado (se entiende básicamente como "recursos naturales"), supeditado a la racionalidad humana (pues el principio de lo real es algo de tipo conceptual, al alcance de la inteligencia humana y manipulable a través de las teorías científicas y las prácticas tecnológicas), y fundamento material para el desarrollo de la humanidad (Wallerstein 2001, pp. 219-22).

Por supuesto, esta constelación de ideas entra en conflicto con la realidad en que nos encontramos en las últimas décadas: graves problemas ecológicos, ineficacia en el uso de esos recursos naturales, y brechas cada vez más grandes entre sociedades ricas y pobres que evidencian el fracaso del modelo moderno de progreso. Es este conflicto entre el modelo de la cosmovisión y el resultado real de su praxis uno - si no el más importante- de los factores que obligan a replantear el modo en que estamos concibiendo y aplicando culturalmente nuestra relación con la naturaleza. Parece claro que la correlación lineal y causal "desarrollo humano a expensas de la explotación del medio, a partir del progreso científico-tecnológico” está errada.

Llegados a este punto, se hace preciso reconsiderar el papel que la técnica tiene en nuestro presente, a partir de la doble relación con la racionalidad (es decir la ciencia en sentido moderno) y la naturaleza, puesto que se la ha considera como la principal herramienta del desarrollo; si hay un error ¿puede ser que la tecnociencia no sea fundamental para que haya desarrollo? Como veremos a continuación, más bien lo que parece es que el error se encuentra en el modo en cómo se entiende su función en la vinculación hombre-medio, aparentemente fuera del contexto de la "ciudad". 


\section{5. la técnica como puente entre la biosfera y la noosfera.}

Si, como se decía algo más arriba, el hombre se presenta a sí mismo en la cosmovisión occidental desgajado de la naturaleza, aunque de alguna manera inmerso en ella (en tanto que orgánicamente sigue siendo una "realidad natural"), esta situación paradójica se expresa eminentemente en la técnica: la técnica es el modo en que el universo mental del hombre (alma, pensamiento, yo, o como queramos determinarlo) se aplica al entorno físico y lo transforma.

De este modo, por el carácter idiosincrásico de la técnica en nuestra especie, se ha entendido generalmente como un producto humano, seguramente el de menos importancia simbólica, debido precisamente a que supone la interacción de la mente con cosas materiales. Llama la atención, a este respecto, cómo en la mayoría de las culturas humanas que han llegado a desarrollar estructuras urbanas se da una correlación entre el desdén por la actividad manual (que ejerce el esclavo, el artesano, el obrero escasa o nulamente cualificado) y la separación simbólica de la naturaleza, amparada en un proceso económico inequívoco, el desarrollo de una infraestructura comercial y administrativa con mayor peso económico que la actividad agropecuaria. Ese desdén -desprecio- por el trabajo manual se mantiene en nuestros días, como podemos comprobar en nuestra división social del trabajo: los campesinos, con salarios de subsistencia, sin acceso a la educación, son en numerosas ocasiones considerados de manera peyorativa por una sociedad que, sin embargo, mira con asombro y envidia a la clase trabajadora exitosa emergente, la que se dedica a la "economía del conocimiento"; los unos, ganándose la vida por debajo de la línea divisoria de la dignidad, por hacerlo "con su cuerpo", y los otros, en los niveles más altos de la consideración social por hacerlo "con la mente". Evidentemente, este esquema se repite al aplicarlo a países pobres (sub-desarrollados, ajenos a las bonanzas de la sociedad post-industrial) y a países ricos (hiper-desarrollados, avecindados en la sociedad del conocimiento). En este contexto, fuertemente arraigado en nuestra cosmovisión y en nuestros días, la técnica es el órganon con el que nos damos a la tarea de darnos las condiciones materiales suficientes para tener una vida satisfactoria, y a partir de las cuales podemos dedicarnos a cosas "realmente humanas", como son el arte, la religión y la política; en la Modernidad, esta idea se expresa así: la tecnología 
es la expresión material y concreta de la ciencia (producto eminentemente "mental").

Es más, la técnica constituiría el ámbito de lo artificial, es decir, de lo totalmente distinto de la naturaleza; como la técnica (o, en su concepción moderna, la tecnología) es un producto de la inteligencia humana, en la cual parece reposar toda su fundamentación, la contraposición entre hombre y mundo se reitera en la contraposición artificial/técnico y natural. Insisto en este conjunto de escisiones y juegos de oposición porque son el punto de partida para comprender el carácter fragmentado de la relación entre tecnociencia y naturaleza en nuestros días, que a su vez parece exigir un esfuerzo titánico para buscar una conciliación entre ambos factores de una gestión ambiental sustentable (López Cerezo 2003, pp. 119-121).

El reto, desde el punto de vista simbólico, consiste en buscar la manera de establecer el equilibrio entre lo natural -externo a nosotros, regido por leyes, material- y lo mental -interno, regulado por la libertad, no material- . Parece que sólo de esta manera se puede compatibilizar el carácter progresivo e ilimitado de la ciencia y el carácter evolutivo y finito de la naturaleza que podemos transformar a través de las tecnologías. Podemos resumir la relación hombre-naturaleza, y el papel que juega en esa relación la técnica en el siguiente esquema:

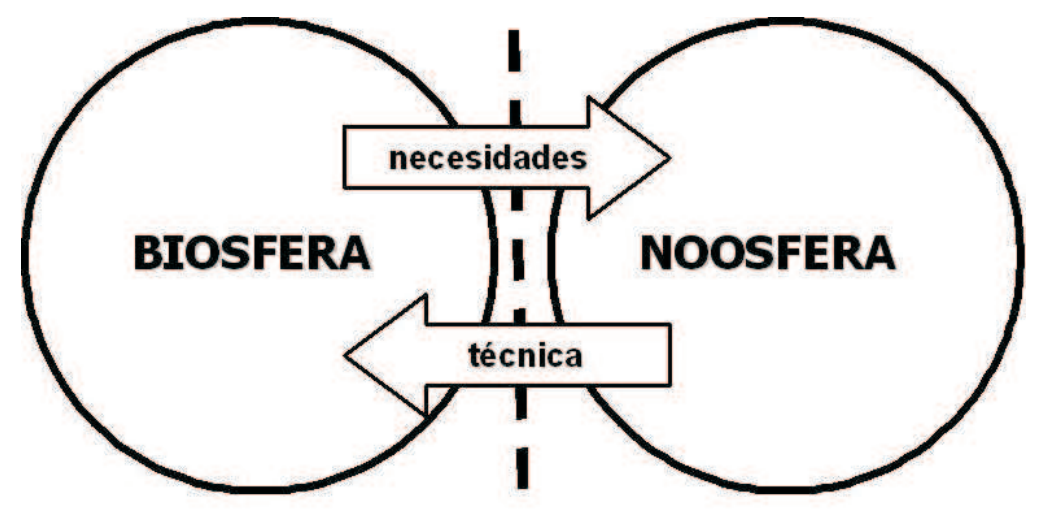

Desde esta perspectiva, el ser humano forma parte de dos ámbitos de realidad (esferas) separadas entre sí, aunque en continua interacción, que podemos denominar biosfera (conjunto de medios en que se desarrollan los seres 
vivos) y noosfera (conjunto de medios en que se dan las ideas y estados mentales). No es que el hombre a veces esté en una biosfera, y en otras en una noosfera, sino que -y ahí la radical paradoja de nuestra situación en el cosmospodemos distinguir entre "nuestro cuerpo" y "nuestro espíritu", como dos elementos integrados, interdependientes, mas estrictamente autónomos entre sí.

Como integrante de la biosfera, el ser humano se sabe identificado con las demás cosas reales; de forma genérica, podríamos decir que, como integrante de biosfera, el hombre está inserto en la naturaleza, con todas las posibilidades y limitaciones que esto trae consigo. De todas ellas, la que más ha interesado es -en términos recientes- su interacción en y con ecosistemas: vivimos "en" un entorno natural, del cual sacamos aquellos recursos que nos resultan indispensables para seguir siendo organismos vivos, y se espera que la inteligencia humana, a través de la técnica, sea capaz de maximizar la cantidad y calidad de beneficios del ecosistema en que se encuentra (tecnologías agropecuarias, modelos sociales de explotación de recursos, etc.), y de minimizar los resultados adversos que supone encontrarse en ese ecosistema (como frío o calor extremos, hambrunas o exposición a desastres naturales, por ejemplo).

Nuestra ventaja en esta esfera, como especie, es la capacidad para cambiar de un ecosistema a otro, a través de la mediación de la técnica, en virtud de la cual somos la única especie que no se adapta al medio, sino que hace que cualquier medio se adapte a nuestras condiciones vitales. Por supuesto, esto es con ciertas restricciones, ya que como "organismo natural", el ser humano está supeditado a las leyes de la naturaleza, y del mundo físico en general, pero podríamos decir que, culturalmente, la biosfera aparece como la esfera limitativa de lo humano: sólo podemos vivir en ciertas condiciones de temperatura, ingesta de caloría, tolerancia a enfermedades, edad, etc.

Frente a esta biosfera, consideramos que la noosfera define la dimensión propia de lo humano: la interacción no es en ecosistemas, sino en sistemas conceptuales, a través del lenguaje. El entramado simbólico resultante nos eleva y separa del resto de la naturaleza, y por lo mismo nos distingue de las demás realidades que se encuentran a nuestro alrededor, idea que se reafirma en el sometimiento de la biosfera a nuestro pensamiento- fundamentalmente el científico- que es capaz de conocer las leyes que rigen al mundo físico para así transformarlo según nuestras necesidades. 


\begin{tabular}{|l|l|}
\hline \multirow{2}{*}{$\begin{array}{l}\text { ETAPAS EN LA } \\
\text { LA CIUDAD }\end{array}$} & a) Ciudad Tradicional (urbe): Central \\
\cline { 2 - 3 } & $\begin{array}{l}\text { b) Ciudad de la Revolución Industrial (metrópolis): } \\
\text { Polinuclear / crecimiento a partir de anillos }\end{array}$ \\
\cline { 2 - 2 } & $\begin{array}{l}\text { c) Ciudad-Red (región o territorio): Nuevas } \\
\text { centralidades en red / Ciudades Globales }\end{array}$ \\
\hline
\end{tabular}

En esta concepción del mundo el problema de la sustentabilidad se construye desde una mirada temerosa ante la naturaleza, que pasa de ser ese gran almacén del que podemos extraer a nuestro antojo la materia prima para alcanzar el bienestar, a un monstruo con la paciencia agotada que parece haber encontrado el momento de la revancha con la especie humana. La tecnología, por su parte, es la herramienta física y conceptual que permite crear un "nuevo mundo", el artificial, de suerte que la distinción natural-artificial es una extensión de la contraposición biosfera-tecnosfera.

\section{Del orden posible al caos aparente: del espacio urbano como integración de lugares al espacio de flujos.}

Las ideas que se presentan en los dos epígrafes anteriores tienen su expresión espacial en el dinamismo urbano a lo largo de su historia. Desde la invención de la ciudad reticular, planificada desde la Antigüedad y atribuida a distintas civilizaciones (en Egipto, Mesopotamia, China, Grecia o Mesoamérica), en un equilibrio entre sus funciones y sus recursos, pasando por el crecimiento de la industrialización y urbanización, se llega a las recientes conceptualizaciones de la ciudad del conocimiento, la ciencia y la tecnología:

"Las ciudades globales son lugares de encuentro cultural y confrontación. Son espacios en desorden. Y para aquellos cuya imaginación (con sus raíces de ilustración) se centra alrededor de los valores de coherencia y orden, este 
tipo [de nuevo urbanismo ] debe ser profundamente problemático. En este contexto, debemos mirar hacia el ideal de la ciudad virtual como una respuesta defensiva y protectora: en un sentido tiene que ver con la negativa o la desaprobación de los medios tecnológicos, de su realidad caótica y difícil; y en otro sentido, involucra el intento por mantener o restablecer los valores (coherencia, orden, comunidad...) del más antiguo ideal (europeo) de urbanismo que ahora parece estar en crisis" (Robins 1999, p. 35).

Y es que la paradoja del llamado "nuevo urbanismo" es que se trata en realidad de una postura de urbanismo conservador, que en gran medida privilegia el individualismo. La radicalización del panorama puede generar lo que Castells ha llamado "ciudades duales": sistemas urbanos que se encuentran social y espacialmente polarizados: comunidades cerradas con alta concentración de ingreso y acceso a todos los beneficios de la tecnología contemporánea, en oposición o aislamiento de amplias áreas urbanas o periferias de pobreza sin inversión pública, sin espacios comunitarios apropiados, situación que se ha generalizado en numerosas ciudades latinoamericanas donde México, Bogotá o Lima son ejemplos con retos todavía insuperables en exclusión, precariedad del hábitat (Burgess y Carmona 2001) y limitantes en su incorporación a los beneficios de las tecnologías, no sólo de la información.

De allí la necesidad de repensar la ciudad desde un amplio espectro de contenidos que incluyan la relación CTS+i. Como bien lo señalan González Romero y Pérez Bourzac (2004, p. 147):

La ciudad es un producto social y por lo tanto es ante todo una unidad con esencia y sentido público. No se puede concebir la ciudad sin lo público como aglutinador y la consideración del espacio público como lugar en la que sus habitantes verifican su presencia, su parte común, su historia (...) El espacio público nos interesa principalmente por dos razones. En primer lugar porque es donde se manifiesta muchas veces con más fuerza la crisis de "ciudad" o de "urbanidad".

Aunque las nuevas tecnologías no son en sí mismas la fuente para lograr una organización lógica de las sociedades que se encuentran bajo transformación de su sentido comunitario en la nueva configuración de su espacio urbano, pueden constituirse, sin embargo, en un instrumento fundamental para planear futuros urbanos sustentables y, en definitiva, socialmente posibles.

El siglo XXI puede ser el tiempo en el que, frente al agotamiento de medios y formas de planificación, habrá de generar las nuevas alternativas para una so- 
ciedad predominantemente urbana, con transformaciones de fondo, donde, más que construir y urbanizar, habrá que generar dinámicas que generen sustentabilidad y urbanidad.

Stephen Graham (1999, p. 10) escribe que: "es ahora claro que el ciberespacio es ampliamente un fenómeno urbano. Se está desarrollando fuera de las ciudades antiguas, y está asociado con nuevos grados de complejidad dentro de las ciudades y los sistemas urbanos, así como amplias áreas urbanas a lo largo del mundo se combinan en un solo sistema metropolitano planetario, globalmente interconectado".

La proliferación de dominios de usuarios múltiples desde que la tecnología de la Internet se difundió masivamente a partir de los inicios de los años 1990 y especialmente desde que la Word Wide Web (www) ha alcanzado a audiencias amplias, se ha comenzado a hablar de "espacio virtual", generando comunidades de usuarios que interactúan, opinan, establecen decisiones o transforman su ciudad, por ejemplo, Bath o Bolonia. A pesar de estos avances, o quizá por ello, la necesidad de interacción humana real parece que ha sido estimulada, lejos de ser disminuida por tales tecnologías.

El crecimiento rápido de las tecnologías de la información y del mundo virtual se refleja en un número creciente de usuarios, sobre todo urbanos. Y es que alrededor de tres cuartas partes de la población mundial habita ciudades. Sin embargo, debe también señalarse que los impactos de la CTS+i en el crecimiento de los asentamientos sigue siendo insostenible desde un punto de vista ambiental y energético, y su impacto positivo sobre la totalidad de la población mundial todavía una promesa por conocer.

La Edge City (USA), o la exposición Les entrées de la ville (París), el auge de las teorías del caos urbano, expresan esta mitificación de la ciudad "desurbanizada" o de la urbanización sin ciudad (...) Se debe considerar a la arquitectura que hace espacio público: los equipamientos culturales. Museos, universidades y bibliotecas como oportunidades de generar espacios ciudadanos (González Romero y Pérez Bourzac 2004, p. 150).

Todo ello acentúa la afirmación de la oposición radical entre lo natural y lo artificial en nuestro modo de concebir la realidad, y acrecienta la certeza de que entre ciudad y naturaleza se abre una brecha cada vez más próxima al abismo. Ahí se encuentra la raíz de la concepción polémica entre respeto a la 


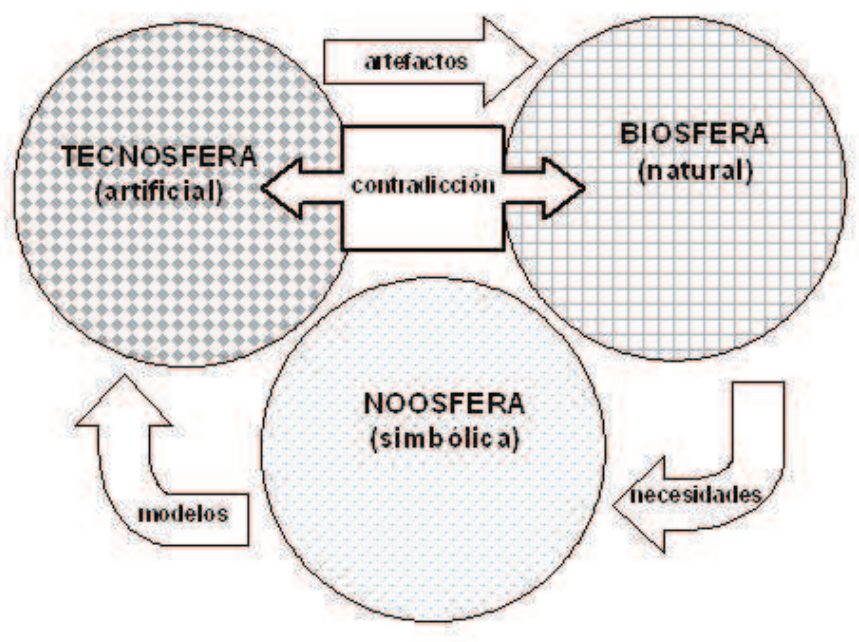

naturaleza, esto es, a las leyes del desarrollo del mundo natural, y respecto al desarrollo tecnocientífico, esto es, a las leyes del desarrollo de la ciencia y la tecnología (López Cerezo 2003, pp. 121-127), de la sociedad urbana postindustrial en su conjunto. Aparentemente, en nuestro presente, nos encontramos en un ciclo pernicioso que quedaría esquematizado de la siguiente manera:

De este modo, la relación bipolar entre biosfera y noosfera, en la que la técnica aparecía como el puente que liga a ambas en tanto que modo en que la inteligencia humana da respuesta a las necesidades que le plantea su supervivencia, se ha ido transformando de manera acelerada en los últimos dos siglos (podemos marcar como hito la consolidación de la revolución industrial en Europa) en una nueva esfera, que depende de la noosfera, pero que ha cobrado autonomía respecto a ella (siguiendo el orden de ideas de Zubiri 1987, pp. 322-330). La tecnosfera se identifica con el sistema tecnológico en un primer momento (siglo XIX y primera mitad del siglo XX) y con sistema tecnocientífico posteriormente (última mitad del siglo XX); esta transformación se expresa en la emergencia de conceptos como "inteligencia artificial", "biotecnología"; "entornos virtuales" o "mundos artificiales"

El ciclo es pernicioso porque, como se muestra en el esquema, de la biosfera surgen necesidades específicas que deseamos cubrir (de inmediato o a futuro), al tiempo que aporta los elementos materiales con que se puede hacerlo; estas 
necesidades son procesadas en la noosfera, de manera simbólica e intersubjetiva, de modo que se plantean modelos de comportamiento de la biosfera y de maximización de sus recursos -de manera coherente con la cosmovisión de quienes se plantean esos modelos-, y los modelos se plasman en artefactos (en este término incluimos tanto los objetos como los procedimientos para crearlos o transformarlos), que a su vez recrean la biosfera y hacen que ésta se comporte según se espera que resuelva mejor las necesidades de quienes dominan los procesos tecnológicos de la tecnosfera. Sin embargo, y éste parece ser el núcleo problemático, tecnosfera y biosfera aparecen incompatibles, pues el desarrollo de la tecnosfera se está haciendo a costa de la merma de la biosfera, lo que nos sigue situando en la senda del desarrollo insustentable.

\section{La ciudad sustentable en la tecnosfera de la sociedad del conocimiento.}

Sin embargo, hay una concepción alternativa de la relación entre biosfera, noosfera y tecnosfera, que rescataría la idea de unidad de lo real a la que, como se decía al comienzo de este artículo, apela toda cosmovisión en cualquier cultura. Esa concepción es aquella que entiende que todo lo real, al menos para el ser humano, es una tecnosfera, es decir, un todo construido en la interacción co-activa (en una interacción en que no hay un elemento activo y otro pasivo) entre naturaleza e inteligencia, entre biosfera y noosfera, y que se expresa en acciones, el conjunto de prácticas de un hombre y de un grupo humano (Zubiri 1986, pp. 329-30). Así, el modelo que permite conjuntar coherentemente medio ambiente y desarrollo científico-tecnológico es del siguiente tipo:

Ahora bien cuál podría ser es el alcance de esta reconstrucción? De entrada, parece que la contraposición entre naturaleza y artefactos es de corte ontológico (es decir, del tipo de "cosa real" con la que nos encontramos), y esa contraposición nos permite distinguir con claridad el tipo de elementos que pertenecen a la biosfera y el de los que pertenecen a la tecnosfera. En este orden de ideas, para conocer qué tipo de realidad es la que nos referimos, bastaría con conocer sus orígenes: lo natural tiene un principio intrínseco de generación, lo artificial tiene un principio extrínseco de generación; ese ha sido el principio epistemológico que, desde la antigüedad griega, ha justificado la contraposición entre lo natural y lo artificial (cfr. Husserl 2000, pp. 89-102) 


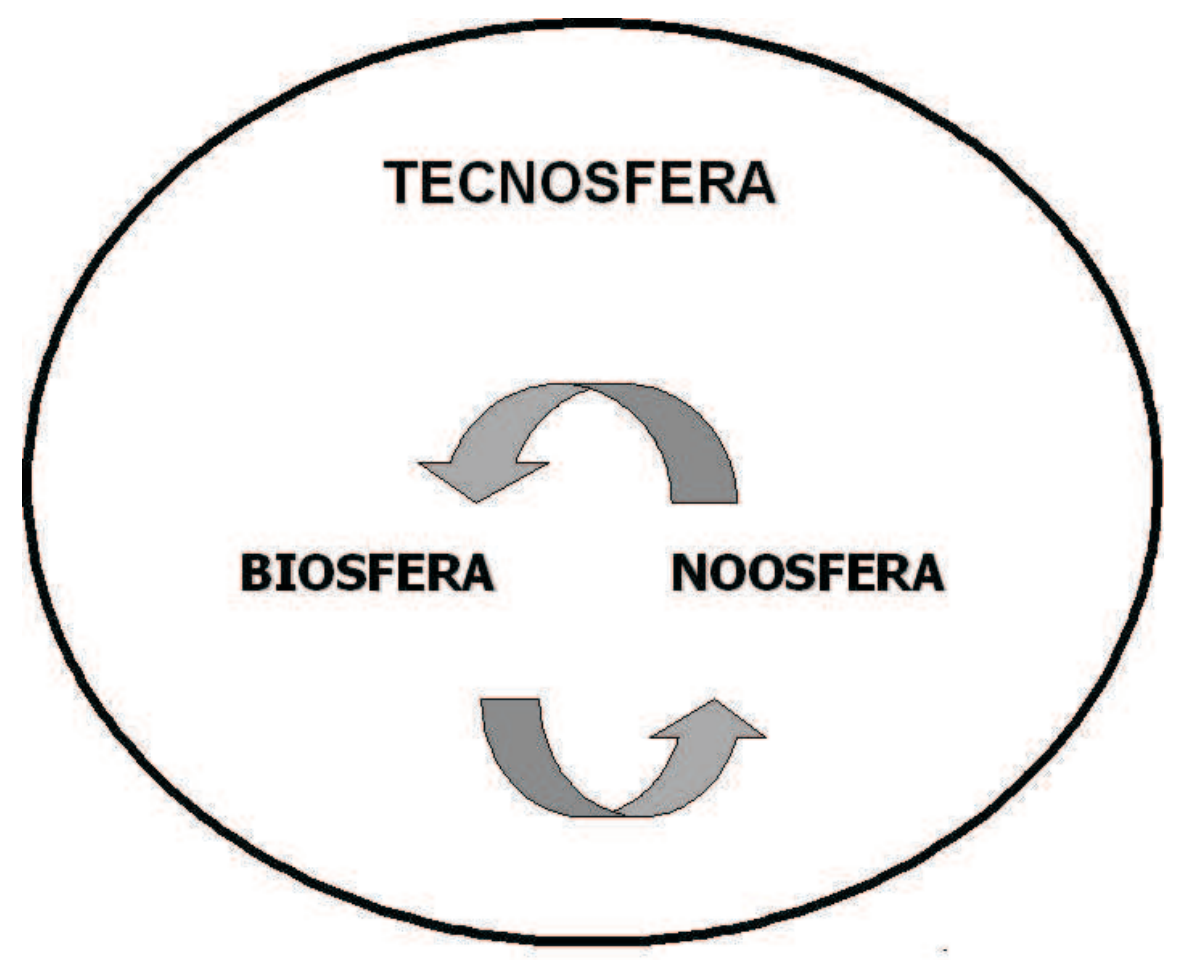

Del mismo modo, esta contraposición se ajusta a dos trayectorias epistemológicas distintas: lo que tiene que ver con la naturaleza constituiría un tipo de conocimiento "genuino", mientras que lo que tiene que ver con la técnica constituye un tipo de conocimiento "instrumental", y por lo tanto, "indirecto”. El principal motivo por el que se da esta contraposición está ligado con el poder del conocimiento causal en la cultura occidental: el conocimiento más sólido es el que explica la causa del fenómeno que tenemos ante nosotros; esta afirmación, que se convierte en certeza en la Antigüedad griega, irá acrisolando la idea de racionalidad científica como métodos y procesos capaces de penetrar en las causas de las cosas y de toda la realidad en su conjunto, puesto que primer principio y causa última parecen confundirse, tal como deja acuñado para la tradición occidental Aristóteles. 
De ese modo, el ámbito de la realidad sobre la que se debe ejercer la indagación sobre causas y principios es lo que los griegos llamaron fisis, que designa a todo lo que es natural en tanto que "tiene un principio intrínseco" de generación y corrupción, y que inmediatamente contraponen a la tecné, lo artificial, lo que tiene un "principio extrínseco" de generación y corrupción: a la fisis le pertenecen las cosas vivas, los fenómenos de la naturaleza, los planetas, las estrellas y los dioses, puesto que todas esas cosas reales son lo que son por algo que les es propio, y sobre lo que la racionalidad puede y ha de indagar; a la tecné le pertenece todo lo hecho por el hombre, ya sea en forma de arte, de herramienta o de técnica en general, puesto que la causas y principios por los que son cosas reales se encuentran fuera de ellos, en la mente del hombre (cuando lo piensa) y en la polis (cuando lo realiza).

Como puede verse, la escisión entre naturaleza y ciudad/técnica no es casual ni caprichosa, tiene que ver con el modelo epistemológico construido por la racionalidad occidental, y aunque sus raíces se encuentran en el pensamiento griego (germen de la filosofía y la ciencia occidentales), llega a su máxima expresión en la Modernidad. La Modernidad es el momento histórico-cultural de Occidente caracterizado por su desarrollo de la ciencia, y su aplicación en la tecnología y la idea de progreso, pero esa caracterización está ligada a una clara concepción antropológica en la que no sólo estamos separados de la naturaleza, sino en la que el hombre despliega su libertad a partir del dominio de ella, esto es, cobra toda su fuerza la idea de que el hombre es básicamente noosfera, y que la libertad se construye a expensas del control de la biosfera por parte de la noosfera.

Este modelo se mantiene con muy pocas variantes desde Galileo (fines del siglo XVI) hasta Heisenberg (principios del siglo XX), en paralelo con la "epistemología del sujeto" desarrollada por la filosofía moderna, desde Descartes (forjador de sustancialidad del "yo") hasta Nietzche (aparición de la idea de la "muerte del sujeto"). Siguiendo, en lo básico, la idea de Kuhn de paradigma científico, se puede afirmar que desde el segundo tercio del siglo XX se viene dando una crisis continuada del paradigma de que la relación hombrenaturaleza en una relación entre dos "cosas", "sustancias" o "ámbitos" distintos e inmiscibles, es decir, de una relación dentro de un sistema "complicado", en el que bastaría con aplicar un exhaustivo proceso analítico para conocer la 
realidad. En este modelo en crisis, se parte de la convicción de que la noosfera puede conocer esa "otra cosa" distinta a ella -la biosfera- para a continuación transformarla según sus necesidades, y a partir de reglas que la propia noosfera puede también conocer y aplicar universalmente (Hernanz 2005, pp. 50-54).

Siguiendo también la propuesta de Kuhn, en esta crisis del paradigma que ha primado en la Modernidad, se da el surgimiento de un paradigma distinto, y en el que parecen resolverse mejor los problemas epistemológicos de la relación entre hombre y naturaleza, y que de manera genérica suele catalogarse como "paradigma de la complejidad. Según este conjunto de propuestas, lo real es efectivamente un sistema en que podemos distinguir entre momentos distintos, pero cuyo conocimiento no puede alcanzarse analizando por separado las características de comportamiento de cada uno de ellos y estableciendo modelos de interacción entre ambos, ya que una de las características de los sistemas complejos es la aparición de propiedades emergentes que no pueden ser comprendidas reduciendo la complejidad a una mera complicación de elementos. De este modo, la tecnosfera no sólo no se reduce al ámbito de las cosas hechas por el hombre, sino que, tal como se presenta en el esquema al comienzo de este apartado, es un fenómeno unitario que exige ser investigado desde su propia complejidad (Lomborg 2003, pp. 67-72).

La época actual demanda una mayor conciencia, acaso como nunca antes en la historia de la ciudad, de la coexistencia de un mundo real y concreto, y de otro mundo abstracto y virtual. Esta conciencia requiere también explorar las posibilidades de integración de ambos entornos. Como resultado, la sustentabilidad territorial y urbana, entendida desde la triada de economía, sociedad y ambiente, constituye el reto formidable de alcanzar, en nuestra condición contemporánea y, sin lugar a dudas, es tema central para la democracia, la gobernabilidad, los derechos humanos y, como señala Lefevbre, el derecho a la ciudad y, por extensión, a la urbanidad.

A pesar de ello las diferencias permanecen, como evidencian los contrastes entre sociedades desarrolladas y subdesarrolladas. Diversas cumbres y foros mundiales encabezados por Naciones Unidas, han llevado a reconocer que una cuarta parte de la población del planeta vive por debajo de la línea de pobreza; que en muchas ciudades, el crecimiento rápido y los problemas ambien- 
tales, sumados a la exclusión del desarrollo, obligan a confrontar los riesgos de una polarización social.

Una de las aportaciones de interés a esta temática, lo constituye el conjunto de trabajos desarrollados por Saskia Sassen, quien hace un análisis sobre las limitantes que hoy en día plantean nuestros modos de representar para entender la ciudad y sus poderes, algunos de los cuales no tienen un referente espacial definido cuando se les sitúa dentro de las complejas dinámicas de la economía, la política y lo cultural. Dice Sassen (2005) que la condición de las llamadas ciudades globales ha posibilitado el surgimiento de nuevos tipos de sujetos políticos, que la globalización y la digitalización se asocian con conceptos como la dispersión o la movilidad.

Aunque la digitalización lleva a pensar en el supuesto de un total desprendimiento del mundo material, es un hecho comprobado que para dar cabida a las nuevas necesidades de un mercado que se expande a través de procesos de urbanización, amplias zonas ecológicas han sufrido daños irreversibles. Sumado a ello, la globalización, la economía de la información y la telemática seguirán siendo conceptos clave asociados a la noción de que el lugar y la localización de procesos no son esenciales. Esto ha situado en riesgo el espacio público y tradicional de las ciudades, el que se vuelve obsoleto frente a las demandas del mercado, que acaba por privilegiar los símbolos y la cultura corporativa de lo trasnacional, por encima de la diversidad cultural o ambiental.

La idea de una economía global sin una localización específica ha llevado a creer que la concentración del poder, de los recursos e incluso de la tecnología, no sólo son consecuentes sino necesarias, generando dispersión geográfica y exclusión de la CTS+i. Pero esto es sólo parte de la historia reciente. La gestión del conocimiento y su distribución desde bases sociales más amplias y sustentables es el reto de una sociedad global más incluyente y más consciente de su sentido humano, o, de manera más amplia, es el reto crucial de la tecnosfera de la sociedad del conocimiento.

\section{Referencias}

Benevolo, L., 1992, Orígenes del urbanismo moderno, Celeste Ediciones, Madrid.

Bentley, I., 2002, "Spatial transformations and their cultural supports", en Urban transformations. Power, people and urban design, Routledge, Londres y Nueva York. pp. 67135. 
Broncano, F. (ed.), 1995, Nuevas meditaciones sobre la técnica, Trotta, Madrid.

Burgess, R. y Carmona, M., 2001, Strategic Planning E Urban Projects. Responses to Globalisation from 15 Cities, Transformations 4, Delft University Press, Delft.

Castells, M., 2000, The Rise of the Network Society, Volumen 3, en The Information Age, Blackwell, Oxford.

Downey, J. y McGuigan, J. (eds.), 1999, Technocities, Sage, Londres.

González Romero, D., Olivares González, A. I. y De Paolini, M. F., 2004, Ciudad, Arquitectura y Medio Ambiente, Universidad de Guadalajara-Universidad Veracruzana, Guadalajara.

González Romero, D.l y Pérez Bourzac, M. T., 2004, "Repensar la ciudad: una necesaria reflexión” en González Romero, D., Olivares González, A. I. y De Paolini, M. F., pp. 145-151.

Graham, S., 1999, "Towards Urban Cyberspace Planning: Grounding the Global through Urban Telematics Policy and Planning” en Downey, J. y McGuigan, J. (eds.)(1999) , pp. 9-33.

Hernanz, J. A., 2006, "La relación hombre-naturaleza como entorno construido", en La Ciencia y el Hombre, vol. XIX, (sept-dic), pp. 69-75.

—, 2005 , "Tecnosfera y mundo", en Ergo, vol. XVI, (marzo ), pp. 43-63.

—, 2004 , "La sustentabilidad en el sistema científico-tecnológico", en La Ciencia y el Hombre, vol. XVII, (sept- dic), pp. 69-75.

Husserl, E., 2000, Ideas, tomo III, en La fenomenología y los fundamentos de las ciencias, UNAM, México.

Ibarra, A. y Olivé, L. (eds.), 2003, Cuestiones éticas en ciencia y tecnología en el siglo XXI, Biblioteca nueva, Madrid.

Lomborg, B., 2003, El ecologista escéptico, Espasa, Madrid.

López Cerezo, A., 2003, “Ciencia, técnica y sociedad”, en Ibarra, A. y Olivé, L. (eds.) (2003), pp. 113-158.

Mitchell, W.J., 2000, E-topia. Urban Life, Jim but not as we know it, MIT Press, Cambridge, Massachussets.

Parker, S., 2004, "The Informational City: Linking the Virtual and Material Urban Worlds", en Urban Theory and the Urban Experience, Routledge, Londres y Nueva York, pp. 164-167.

Quintanilla, M. A., 1995, "La construcción del futuro”, en Broncano, F. (ed.) (1995), pp. 201-215.

Read, Stephen, Rosemann, J. y van Eldijk, J. (eds.), 2005, Future City. Spon Press, Londres y Nueva York.

Robins, K., 1999, "Foreclosing on the City? The Bad Idea of Virtual Urbanism" en Downey, J. y McGuigan, J. (ed.) (1999), pp. 34-59. 
Sassen, S., 2005, "Reading the city in a global digital age: between topographic representation and spatialized power projects" en Read, S., Rosemann, J. y Van Eldijk, J. (eds.) (2005), pp. 145-155.

Wallerstein, I., 2001, Conocer el mundo, saber el mundo: El fin de lo aprendido, Siglo XXI, México.

Winfield Reyes, F. N., 2005, "Sobre el impacto energético reflexiones para la sostenibilidad", en La Ciencia y el Hombre, Vol. XVIII, (Mayo-Agosto), pp. 33-36.

_, 2004 , "La Revolución Industrial: orígenes del urbanismo moderno", en La Ciencia y el Hombre, Vol. XVII, (Enero-Abril), pp. 57-60.

, 1980, Inteligencia Sentiente, Alianza Editorial, Madrid.

Zubiri, X., 1986, Sobre el hombre, Alianza Editorial, Madrid.

Recibido el 2 de Febrero de 2011

Aceptado el 15 de Febrero de 2011 